\title{
Risk Assessment of Canine Distemper in the Distribution Area of Giant Panda in Sichuan, Shaanxi and Gansu Provinces, China
}

\author{
Weigeng Shao ${ }^{1}$, Feng Jiang ${ }^{2,3}$, Liya Huang ${ }^{4}$, Xiaolong Wang ${ }^{2,3, *}$ \\ ${ }^{1}$ Heilongjiang Academy of Forestry and Environment, Qiqihar 161005, China \\ ${ }^{2}$ College of Wildlife Resources, Northeast Forestry University, Harbin 150040, China \\ ${ }^{3}$ Center of Conservation Medicine \& Ecological Safety, Northeast Forestry University, Harbin 150040, China \\ ${ }^{4}$ Changbai Mountain Academy of Sciences, Antu 133613, China
}

Received 3 September 2017

Accepted 10 November 2017

\begin{abstract}
Giant panda is the world-class precious endangered species, facing the canine distemper and other important infectious diseases on its wild and captive population of a serious threat. In this study, we used MaxEnt model and combined with ArcGIS analysis to predict the potential risk of canine distemper to giant panda habitat in Sichuan, Gansu and Shaanxi Provinces, China. The results showed that $35.05 \%$ and $19.47 \%$ of the distribution areas of the giant pandas were in the high risk and medium risk of canine distemper, respectively. The canine distemper pose a great risk to the healthy survival of giant pandas in China. In future, epidemic prevention, vaccine development and application of wild animals should be enhanced so as to effectively protect the giant panda.
\end{abstract}

Keywords: Giant Panda, canine distemper, MaxEnt model, risk assessment

\section{川、陕、甘三省大熊猫分布区犬瘟热风险评估}

\author{
邵伟庚 ${ }^{1}$, 江峰 ${ }^{2,3}$, 黄利亚 $^{4}$, 王晓龙 ${ }^{2,3, *}$ \\ 1.黑龙江省森林与环境科学研究院, 齐齐哈尔 161005 , 中国; \\ 2.东北林业大学野生动物资源学院，哈尔滨 150040 , 中国; \\ 3.东北林业大学保护医学与生态安全研究中心, 哈尔滨 150040, 中国; \\ 4.长白山科学研究院, 安图 133613, 中国
}

\begin{abstract}
摘要: 大熊猫是世界级珍贵濒危物种, 正面临犬瘟热等重要传染病对其野生和圈养种群的严重威 胁。本研究采用 MaxEnt 模型并结合 ArcGIS 分析, 预测犬瘟热对我国四川、甘肃和陕西大熊猫 栖息地潜在风险。结果显示, 35.05\%和 19.47\%的大熊猫活动区分别处于犬瘟热高风险和中风险 威胁之下, 犬瘟热对我国大熊猫健康生存构成极大的风险。因此应加强对大熊猫活动区域内野生 动物疫情防范, 提升野生动物的疫苗研制与应用, 以有效保护大熊猫。
\end{abstract}

关键词: 大熊猫, 犬瘟热, MaxEnt 模型, 风险评估

* Corresponding author: E-mail: yttuhh@yeah.net. Post address: College of Wildlife Resources, Northeast Forestry University, Harbin 150040, China 
大熊猫（Ailuropoda Melanoleuca）是我国特有 的生物多样性保护旗舰物种 ${ }^{[1]}$, 目前野生种群数量 为 1864 只, 栖息地面积为 258 万公顷 ${ }^{[2]}$, 分布于川、 陕、甘三省的六大山系 ${ }^{[3]}$ 。自 1983 年至 2015 年, 我国至少有 12 只大熊猫感染犬瘟热（Canine

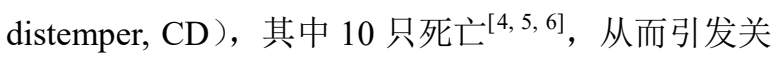
注。CD是由犬瘟热病毒 (Canine distemper virus, CDV) 引发的一种急性、烈性的病毒性传染病, 动 物感染后致死率极高, 可达 $100 \%{ }^{[7]}$ 。CDV全球均有 分布, 无特定宿主屏障, 可感染多种动物 ${ }^{[8,9,10]}$, 也 是引发大熊猫感染性腹泻的主要病原体 ${ }^{[11]}$ 。野生大 熊猫异常珍贵、数量稀少, 踪迹很难发现, 开展大 规模野外研究困难。因此本研究采用目前广泛使用 的MaxEnt (Maximum Entropy)模型 ${ }^{[12,13]}$, 结合地理 信息系统分析大熊猫栖息地内的犬瘟热空间分布及 风险情况, 为大熊猫保护对策的制定提供理论依据。

\section{1. 材料与方法}

\section{1 研究区域}

研究区域位于川、陕、甘三省的岷山、扔崃、 大相岭、小相岭、凉山和秦岭这六大山系的大熊猫 的栖息地, 地理位置为 $\mathrm{E} 101.85^{\circ} \sim 108.799^{\circ}$, $\mathrm{N} 28.2^{\circ} \sim 34.01^{\circ}$ 之间, 行政区域包括 45 个县（市, 区) ${ }^{[14]}$ 。

\section{2 川、陕、甘三省 $C D$ 空间分布分析}

(1) $\mathrm{CD}$ 样本数据环境数据的收集和处理

在 NCBI 的基因库（GenBank）以及世界动物 卫生组织 (OIE) 等网站中收集 CD 地理坐标信息, 以 Excel 表格存储为".csv" 格式数据。从世界气象 数据库（Global Climate Date）下载 68 个空间分辨 率为 $30 \mathrm{arc}-$ seconds 的环境因子数据, 并转换成 MaxEnt 软件所需要的".asc"格式。

(2) MaxEnt 模型运算及处理

MaxEnt模型是由Steven Phillips等人基于最大 熵原理开发的一种生态位模型, 它是通过物种已知 实际地理分布点和限制该物种分布的环境变量等约 束条件, 并建立二者之间的关系模型, 探寻在环境 变量等约束条件下的最大分布, 摘达到最大时即为 该物种出现的概率分布作为物种实际分布 ${ }^{[15,16]}$ 。因
此MaxEnt模型可以评价或预测物种给定环境等约 束条件下适宜性潜在分布区域 ${ }^{[17]}$, 并且该模型在濒

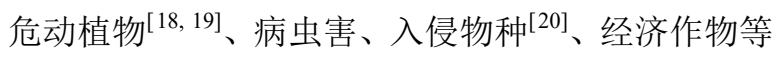
方面均有相关研究。而模型给出的AUC (Areas under receiver operator characteristic curves)值越接近 1, 则 表明预测结果越好。使用 MaxEnt 3.3.3k 版本 (http://www.cs.princeton.edu/ schapire/maxent/), 将 采集的数据按测试集 $25 \%$ 和训练集 $75 \%$ 随机分组, 选择刀切法, 重复次数为 10 , 其他参数为默认值。 运算结果采用ArcGIS 10.2 显示, 叠加川、甘、陕三 省的包括省、市、县 (区) 行政区划图层, 剪裁后 分析。

\section{3 大熊猫分布区 $\mathrm{CD}$ 空间分布分析}

利用 ArcGIS 10.2 软件将大熊猫主要栖息地区 域叠加到川、甘、陕三省 $\mathrm{CD}$ 分布图中, 沿区域边 界线剪裁并分析。打开大熊猫栖息地区域属性表, 在 “Property” 中选择添加面积 (Area) 字段, 并在 “Calculate System” 中选择投影坐标系统(PCS), 把 前述栖息地区域属性表复制、导入 Excel 中。

通过软件中 “数据框属性” 经纬度网格将栖息 地均分为最小单元格 $\left(0.1^{\circ} \times 0.1^{\circ}\right)$, 并提取单元格 中 0 (蓝) $\sim 1$ (红) 的属性值, 该属性值即为 $\mathrm{CD}$ 的概率值，值越大（越红）则表明该地区的风险越 高。将该属性值数据导出, 复制入 Excel 表格中, 然后统计大熊猫栖息地中六大山系最小单元格个数 以及属性值为高、中、低的单元格个数, 最后计算 各个山系不同风险的面积以及风险比例。

\section{2 结果分析}

\section{1 川、陕、甘三省 $C D$ 风险分析}

川、陕、甘三省整体 $\mathrm{CD}$ 风险水平呈现为从东 南向西北逐级降低的趋势, 四川省高风险区域面积 较大 (图 1)。四川省中部和东部 (E102.31 $1^{\circ}$ 106.44 ${ }^{\circ}$,

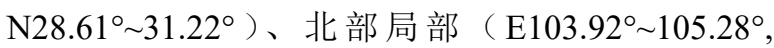
$\mathrm{N} 31.79^{\circ} \sim 32.66^{\circ}$ ）, 以及甘肃省东南部 $\left(\mathrm{E} 104.24^{\circ} \sim 105.71^{\circ}, \mathrm{N} 32.62^{\circ} \sim 33.93^{\circ}\right)$ 处于 $\mathrm{CD}$ 高风 险区域。其他地区则分别处于 $\mathrm{CD}$ 中等风险至极低 风险概率区域。 


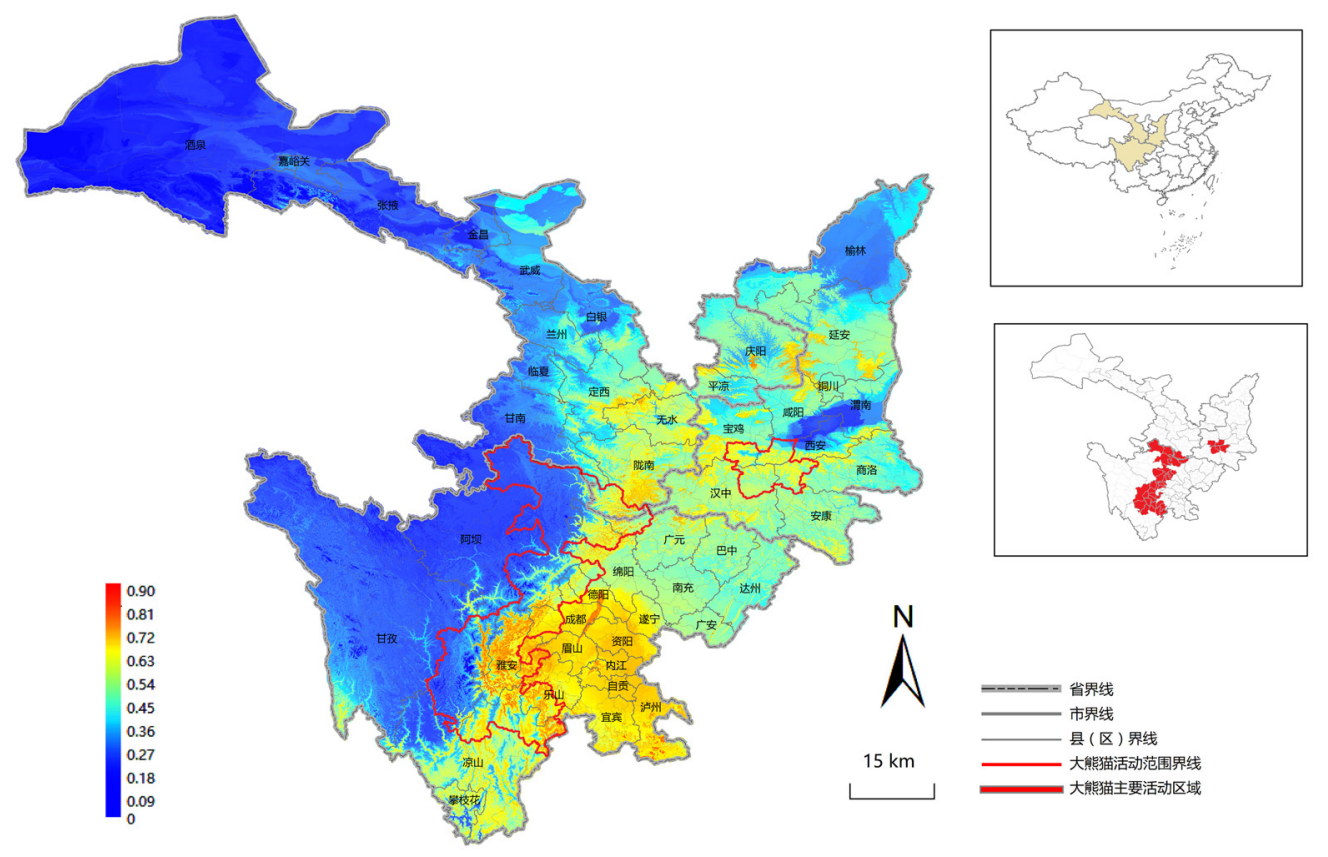

图 1 川、陕、甘三省犬瘟热风险图

Figure 1. The Canine distemper risk diagram in Sichuan, Shanxi and Gansu provinces

$\mathrm{AUC}$ 检测显示, $\mathrm{CD}$ 的 AUC 平均值为 0.949 (图 2)。

\section{2 大熊猫主要栖息地 $C D$ 风险分析}

大熊猫主要活动区域可分为 $A 、 B$ 这 2 大区域 进行分析（图 3)。A 区域包括怅山、扔崃、大相岭、
小相岭、凉山, 此区域 CD 风险同样呈现从东南向 西北逐级降低的趋势，其东部、东北部和东南部处 于 $\mathrm{CD}$ 高风险等级, 高、中风险区域分别占总研究 区域面积的 $35.05 \%$ 和 $13.78 \%$ （表 1)。B 区域包括 秦岭山系 (陕西境内), $\mathrm{CD}$ 风险处于中等风险水平, 中风险区域占总研究区域面积的 $5.96 \%$ 。

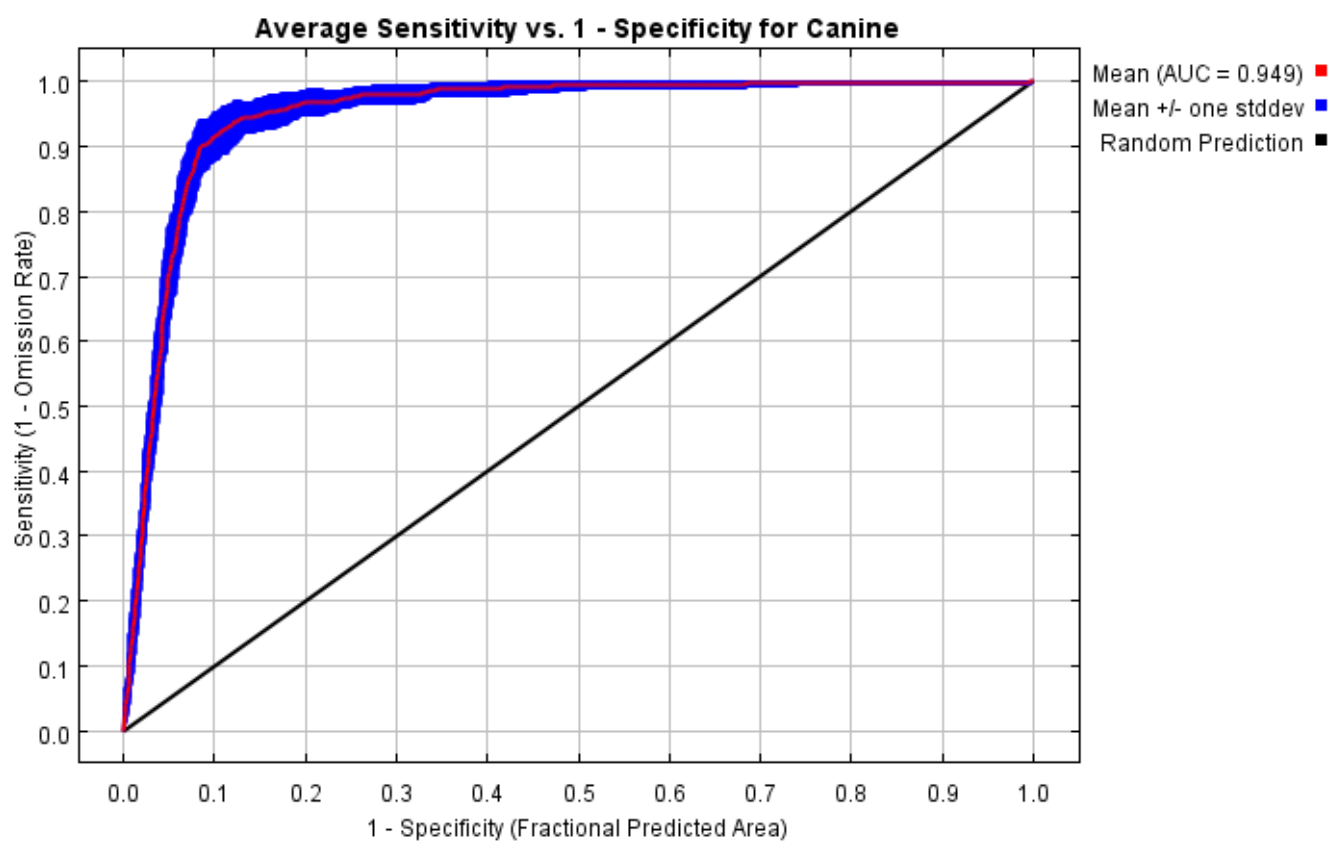

图 2 犬瘟热风险分布 $\mathrm{ROC}$ 曲线

Figure 2. ROC curve of Canine distemper risk distribution

注：ROC 曲线是“受试者工作特征曲线”( receiver operating characteristic curve ) 的简称。 


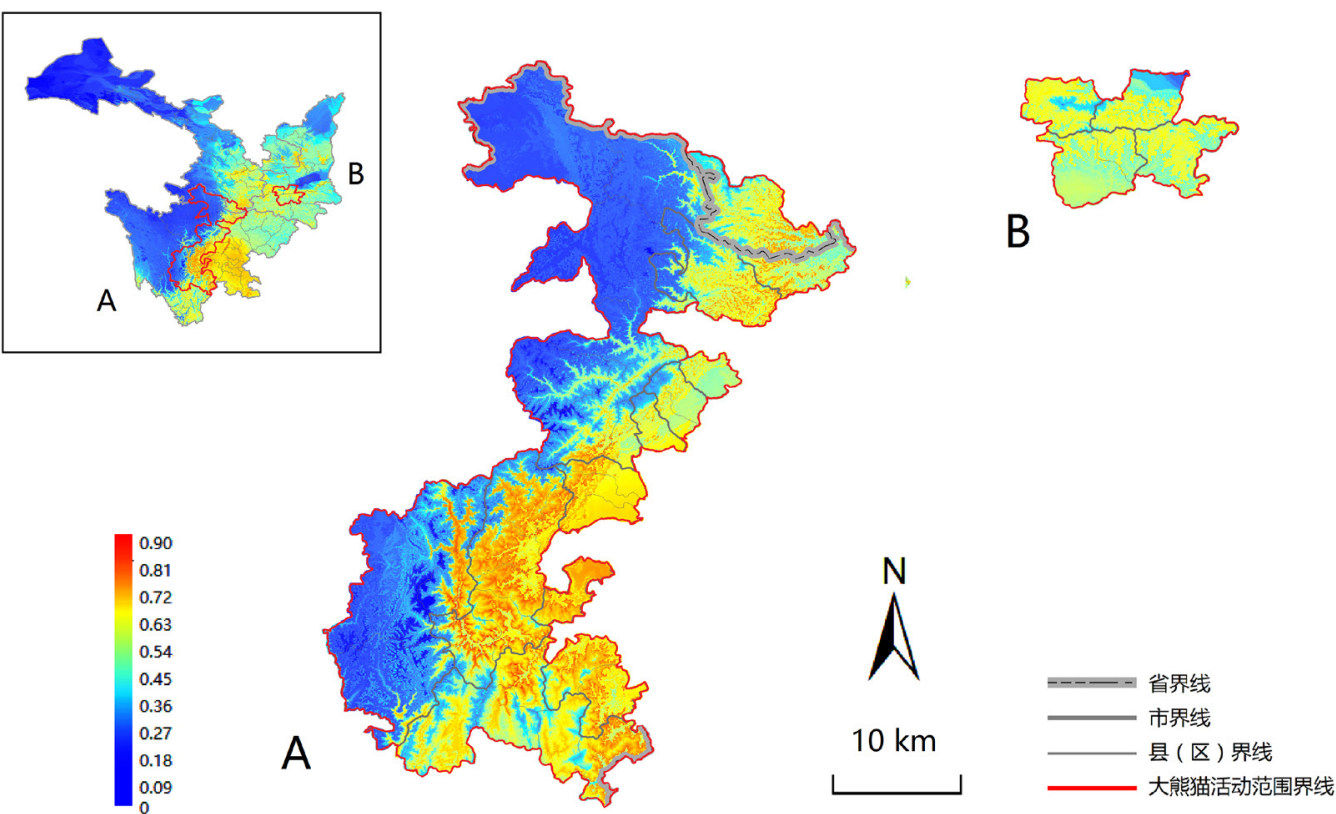

图 3 大熊猫主要活动区域内犬瘟热风险分析图

Figure 3. Analysis of Canine distemper risk in the main active area of giant panda

表 1 大熊猫分布六大山系风险等级面积百分比

Table 1 Risk rating area percentage of six mountain systems in Giant panda habitat

\begin{tabular}{|c|c|c|c|c|c|c|}
\hline \multirow{4}{*}{$\begin{array}{c}\text { 山系 } \\
\text { Mountain } \\
\text { system }\end{array}$} & \multirow{2}{*}{\multicolumn{2}{|c|}{$\begin{array}{c}\text { 高风险 } \\
\text { High risk }\end{array}$}} & \multirow{2}{*}{\multicolumn{2}{|c|}{$\begin{array}{c}\text { 中风险 } \\
\text { Medium risk }\end{array}$}} & \multicolumn{2}{|c|}{ 低至极低风险 } \\
\hline & & & & & \multicolumn{2}{|c|}{ Low to extremely low risk } \\
\hline & 面积 $\left(\mathrm{km}^{2}\right)$ & 比例 & 面积 $\left(\mathrm{km}^{2}\right)$ & 比例 & 面积 $\left(\mathrm{km}^{2}\right)$ & 比例 \\
\hline & Area & Proportion & Area & Proportion & Area & Proportion \\
\hline 岷 山 & 9421.32 & $7.09 \%$ & 9889.61 & $7.45 \%$ & 31180.06 & $23.48 \%$ \\
\hline \multicolumn{7}{|l|}{ Minshan } \\
\hline 邛 崃 & 12047.08 & $9.07 \%$ & 5511.74 & $4.15 \%$ & 16106.54 & $12.13 \%$ \\
\hline \multicolumn{7}{|l|}{ Qiong lai } \\
\hline 大相岭 & 6117.47 & $4.61 \%$ & 0.00 & 0.00 & 0.00 & 0.00 \\
\hline \multicolumn{7}{|l|}{$\begin{array}{l}\text { Daxiangling } \\
\text { mountains }\end{array}$} \\
\hline 小相岭 & 6468.20 & $4.87 \%$ & 1758.08 & $1.32 \%$ & 6770.00 & $5.10 \%$ \\
\hline \multicolumn{7}{|c|}{$\begin{array}{l}\text { Xiaoxiangling } \\
\text { mountains }\end{array}$} \\
\hline 凉 山 & 12492.23 & $9.41 \%$ & 1138.94 & $0.86 \%$ & 0.00 & 0.00 \\
\hline \multicolumn{7}{|l|}{ Liangshan } \\
\hline 秦 岭 & 0.00 & 0.00 & 7555.20 & $5.69 \%$ & 6361.80 & $4.79 \%$ \\
\hline \multicolumn{7}{|l|}{ Qin ling } \\
\hline $\begin{array}{l}\text { 合 计 } \\
\text { Total }\end{array}$ & 46546.28 & $35.05 \%$ & 25853.58 & $19.47 \%$ & 60418.40 & $45.49 \%$ \\
\hline
\end{tabular}




\section{3. 讨论}

结果研究显示, 大熊猫栖息地中约 54.51\%区域 处于 $\mathrm{CD}$ 高风险和中风险水平 (图 3, 表 2), 整体 呈现为西北向东南方向 $\mathrm{CD}$ 风险强度逐渐增加的趋 势，与川、陕、甘三省整体风险趋势相同。

大熊猫栖息地约 $85 \%$ 的面积在四川境内, 且野 生种群数量 (1387 只) 占全国总数的 $74.4 \%{ }^{[2]}$; 四 川省 $\mathrm{CD}$ 风险等级高于甘肃和陕西省 (图 1), 且高 风险区域主要在四川境内, 甘肃省东南部也处于高 风险区域（图 3, 表 1), 这表明 $\mathrm{CD}$ 对该区域大熊 猫的生境健康存在较高的潜在风险。

我国对大熊猫病毒性疾病的流行病学调查研究 尚显不足, 家犬以及其它野生易感动物的 $\mathrm{CD}$ 流行情 况亦多不清楚, 家犬免疫率偏低 ${ }^{[21]}$, 都给大熊猫保 护带来了无法克服的困难。

关于野生动物疫苗的研制及应用在我国还未成 为公共卫生的重点, 对野生动物免疫研究投入并不 充足 ${ }^{[22,23]}$, 野生动物的疫苗研制工作还需提升 ${ }^{[24]}$ 。 因此在大熊猫活动区域内, $\mathrm{CD}$ 预防工作应成为保护 大熊猫的重要内容。在大熊猫 $\mathrm{CD}$ 高风险区域, 需要 采取有效的措施, 例如可将大熊猫活动区域内的家 犬或肉犬进行强制免疫或者统一管理, 加强大熊猫 疫苗研制工作，有效保护大熊猫。

致谢：国家重点研发计划重点专项（2017YFD0501702）资助。

\section{参考文献}

[1] Wen Z, Yang S, Shan T, et al. Virome comparisons in wild-diseased and healthy captive giant pandas. Microbiome, 2017, 5(1):90.

[2] http://www.forestry.gov.cn/

[3] 李俊清, 申国珍, 等. 大熊猫栖息地研究. 北京: 高 等教育出版社, 2012: 17 18.

[4] 李金中, 夏咸柱, 何洪涁, 等. 基因序列分析确诊大 熊猫的犬瘟热病毒感染. 中国兽医学报, 1999, 19 ( 5 ) : 448 450.

[5] 高玉伟, 夏咸柱, 鞠会艳, 等. 大熊猫血清犬瘟热病 毒中和抗体调查. 第十一次全国养犬学术研讨会论 文集，2005: 240 243.

[6] 胡彦博, 秦晓东, 梁晚枫. 大熊猫犬瘟热研究进展. 吉 林畜牧兽医，2016，37(2)：12 15.
[7] Wyllie SE, Kelman M, Ward MP. Wyllie SE, Kelman M, Ward MP. Epidemiology and clinical presentation of canine distemper disease in dogs and ferrets in Australia, 2006-2014. Australian veterinary journal, 2016, 94(7), pp.215-22.

[8] Lempp C, Spitzbarth I, Puff C, et al. New Aspects of the Pathogenesis of Canine Distemper Leukoencephalitis. Viruses, 2014, 6(7):2571-601.

[ 9 ] Martinezgutierrez M, Ruizsaenz J. Diversity of susceptible hosts in canine distemper virus infection: a systematic review and data synthesis. Bmc Veterinary Research, 2016, 12(1):1-11.

[10] Carpenter MA, Appel M.J, Roelke-Parker M.E, et al. Genetic characterization of canine distemper virus in Serengeti carnivores. Vet Immunol Immunopathol, 1998, 65 (2-4): 259-266.

[11] Feng N, Yu Y, Wang T, et al. Fatal canine distemper virus infection of giant pandas in China. Scientific Reports, 2016, 6:27518.

[12] Johnson T L, Bjork J K H, Neitzel D F, et al. Habitat Suitability Model for the Distribution of Ixodes scapularis (Acari: Ixodidae) in Minnesota. Journal of Medical Entomology, 2016(3):3 8.

[13] 王运生, 谢丙炎, 万方浩, 等. ROC 曲线分析在评 价入侵物种分布模型中的应用. 生物多样性, 2007, $15(4): 65-372$.

[14] 周洁敏. 大熊猫生境质量评价体系研究[D]. 北京林 业大学, 2008.

[15] Phillips S J, Dudik M. Modeling of species distributions with Maxent: new extensions and a comprehensive evaluation. Ecography, 2008, 31(2): 161 175.

[16] 邢丁亮, 郝占庆. 最大熵原理及其在生态学研究中 的应用. 生物多样性, 2011，(03): 295 302.

[17] 刘振生, 高惠, 滕丽微, 等. 基于 MAXENT 模型的 贺兰山岩羊生境适宜性评价. 生态学报, 2013, (22): 7243-7249.

[18] 万基中, 王春晶, 韩士杰, 等. 应用 GIS 和 Maxent 预测南方红豆杉潜在地理分布及其保护建议. 江苏 农业科学, 2014，42(7) : 349 352.

[19] 马松梅, 聂迎涁, 耿庆龙, 等. 气候变化对蒙古扁 桃适宜分布范围和空间格局的影响. 植物生态学报, 2014, 38 (7) : 262 269.

[20] 杨会枫, 郑江华, 吴秀兰, 等. 基于 Maxent 模型的 西伯利亚蝗虫在新疆潜在分布预测研究. 新疆农业 科学, 2016, 53 (1) 43 50.

[21] 张菲, 张守峰,唐青, 等. 我国狂犬病现状与防控意 见. 中国人兽共患病学报, 2016, 26 (4): 381 387.

[22] 王否, 李天松, 刘玉秀, 等. 犬瘟热新型疫苗研究 进展. 动物医学进展, 2011，32（2）99-103.

[23] 夏咸柱. 野生动物疫病与公共卫生. 中国自然医学 杂志, 2007, 9 (1): 72 77.

[24] 夏咸柱, 俞永新, 侯云德, 等. 加强我国狂犬病防 控. 中国病毒病杂志, 2011，1（3): 161 162. 